OPEN ACCESS

Edited by:

Jaimo Ahn

University of Michigan, United States

Reviewed by:

Konstantinos Markatos,

Salamina Medical Center, Greece

Richard Yoon

Jersey City Medical Center,

United States

*Correspondence:

Kai Yang

yangkairalph@163.com

Xiaoyan X

1049267163@qq.com

${ }^{\dagger}$ These authors have contributed equally to this work

Specialty section:

This article was submitted to

Orthopedic Surgery,

a section of the journal

Frontiers in Surgery

Received: 10 January 2021

Accepted: 23 August 2021

Published: 21 September 2021

Citation:

Deng J, Zhang S, Yu Y, Zhang L,

Zhang $L$, Jiang $W$, Yang $K$ and $X i X$ (2021) Efficacy of Hemiarthroplasty vs. Locking Plate Fixation for Proximal Humerus Fractures: A Meta-Analysis. Front. Surg. 8:651554. doi: 10.3389/fsurg.2021.651554

\section{Efficacy of Hemiarthroplasty vs. Locking Plate Fixation for Proximal Humerus Fractures: A Meta-Analysis}

\author{
Jiali Deng ${ }^{1+}$, Shuai Zhang ${ }^{2+}$, Yuanyuan Yu ${ }^{1}$, Li Zhang ${ }^{1}$, Li Zhang ${ }^{1}$, Wen Jiang ${ }^{3}$, Kai Yang ${ }^{4 *}$ \\ and Xiaoyan $\mathrm{Xi}^{1 *}$ \\ ${ }^{1}$ Department of Orthopedics, Clinical Medical College and The First Affiliated Hospital of Chengdu Medical College, Sichuan, \\ China, ${ }^{2}$ Department of Anesthesiology, Clinical Medical College and The First Affiliated Hospital of Chengdu Medical College, \\ Sichuan, China, ${ }^{3}$ Department of General Medicine, The Third People's Hospital of Chengdu, Sichuan, China, ${ }^{4}$ Emergency \\ and Business Management Office, Chengdu Center for Disease Control and Prevention, Sichuan, China
}

Background: Proximal humerus fractures are common in a clinic and account for $\sim 6 \%$ of all adult fractures. Hemiarthroplasty $(\mathrm{HA})$ or locking plate (LP) fixation is currently recommended for the treatment of complex proximal humerus fractures (PHFs); however, there is no uniform standard for optimal surgical treatment or functional recovery. We conducted a meta-analysis to compare the efficacy of LP and HA in the treatment of PHFs.

Methods: Relative studies associated with HA and LP were searched in December 2020 in the PubMed, Embase, Cochrane Library, and OVID databases. The quality of the studies, functional outcomes (including the Constant-Murley score (CMS), American Shoulder and Elbow Surgeons Score (ASES), Simple Shoulder Test (SST), Short Form Health Survey (SF-12v2), complications, and reoperation rate were extracted and analyzed with the Stata 14.0 software.

Results: A total of 958 patients from 12 studies were included in the meta-analysis, which showed that patients treated with LP had a significantly lower reoperation rate, a higher complication rate, and a higher CMS score than those treated with HA. There were no significant differences in ASES, SST, or SF-12v2 scores between treatment groups.

Conclusions: Compared with HA, LP exhibited better clinical efficacy in some aspects. However, large sample and randomized, controlled studies are needed for further validation.

Keywords: hemiarthroplasty, proximal humerus fractures, meta-analysis, locking plate fixation, functional recovery

\section{INTRODUCTION}

Proximal humerus fractures are fractures that are usually attributed to osteoporosis (1) and are mostly caused by low-energy trauma $(2,3)$. It is a common clinical problem and accounts for $\sim 6 \%$ of all adult fractures (4). The incidence of proximal humerus fractures (PHFs) in elderly patients is second only to the incidence of hip and distal radius fractures; thus, PHFs have become a serious public health problem $(5,6)$. The ideal treatment for PHFs remains controversial. Conservative measures and/or surgical management are still considered as the mainstays of treatment (7). 
Among them, open reduction and internal fixation (ORIF), hemiarthroplasty (HA), and reverse shoulder arthroplasty (RSA) are the primary methods of surgical treatment (8).

Although there are many surgical methods for PHF, there is still no unified standard for the selection of surgical methods. Therefore, the choice of surgical method depends mostly on the experience and personal preference of the surgeon (9). In recent decades, $\mathrm{HA}$ has become the treatment of choice for severe comminuted and displaced fractures of PHFs. However, postoperative joint function was not satisfactory. There were relatively high postoperative complications (10), and the rate of nonunion of large tubercles was as high as $17 \%(11,12)$. Currently, the development of internal fixation technology, especially the appearance of locking plates (LPs), has provided a new idea for the treatment of PHFs $(13,14)$. However, despite the improvement of fixation techniques may still be inaccurate. The risk of losing fixation, nonunion, or ischemic necrosis is considered too high to attempt internal fixation $(15,16)$.

Although LP or HA is currently recommended for the treatment of complex PHFs, there remains some controversy. In addition, there is no uniform standard for optimal surgical treatment or functional recovery. To date, only a few related randomized clinical trials (RCTs) have been carried out, and some reported systematic reviews could not provide convincing evidence for clinical decision-making (17). In this study, we intended to explore the differences in complications and efficacy between LP and HA in the treatment of PHFs by meta-analysis to provide a reference for the selection of surgical methods for PHFs.

\section{METHODS}

\section{Search Strategy}

Two of the authors independently searched the PubMed, Cochrane Library, Embase, and OVID electronic literature databases in December 2020. A combination of different terms and synonyms of keywords was used as follows: proximal humeral fracture, shoulder fracture, locking plate, plate fixation, plate internal fixation, PHILOS plate, locking compression plate, arthroplasty, joint replacement, and hemiarthroplasty. Additionally, through the search of references from previously published randomized trials, reviews, and meta-analyses for additional eligible studies, relevant articles, and reference lists were searched to avoid original omissions.

\section{Eligibility Criteria Inclusion Criteria}

(1) Randomized or nonrandomized controlled trials (evidence at or above level III); (2) patients with Neer II to IV fractures who were treated with LP and HA; (3) patients with a follow-up term of at least 3 months, functional outcomes, complications, and reoperation rate were used as results of the evaluation; and (4) relevant outcome indicators were included in the research results, and reliable data could be extracted from the full text.

\section{Exclusion Criteria}

(1) Other treatment methods, such as nonsurgical treatment, intramuscular nail fixation, and reverse shoulder arthroplasty; (2) exclusion of pathological fractures, multiple nonproximal humeral fractures, old fractures, etc.; (3) case report, systematic review, and animal experiments; (4) articles that fail to extract valid data and evidence lower than level III; and (5) without fulltext.

\section{Data Extraction}

Two reviewers extracted the data according to the inclusion and exclusion criteria independently, and quality evaluation and data extraction were also carried out. If there was a disagreement, a further decision was adjudicated by the third author. The extracted data included the following: authors, publication date, research type/evidence level, sample size, fracture classification, follow-up term, etc. The effectiveness evaluation indices included functional outcomes [including the Constant-Murley score (CMS), American Shoulder and Elbow Surgeons Score (ASES), Simple Shoulder Test (SST), Short Form Health Survey (SF-12v2)], complications, and reoperation rate. For continuous outcomes, the mean and standard deviation (SD) and participant numbers were extracted. If these data were not available, the data were calculated using the methods described by Hozo (18).

\section{Statistical Analysis}

Bicategorized index data were calculated by the odds ratio (OR) and $95 \%$ confidence intervals (CI), and the combined odds ratio (pooled OR) was calculated using the Mantel-Haenszel model. Continuity index data were calculated using the standardized mean difference (SMD) and 95\% CI, and the combined SMD was determined using the random or fixed effects model. The heterogeneity between documents was determined by calculating $Q$ and $I^{2}$ statistics. If the heterogeneity $\left(I^{2}\right)>20 \%$, the results were combined with a random effects model; otherwise, a fixed effects model was used. Publishing bias was calculated with the Begg method. All the data were collected and analyzed using the Stata 14.0 software (Stata, College Station, TX, United States). $P<0.05$ was considered to be statistically significant.

\section{RESULTS}

\section{Included Studies}

A total of 1,574 potential references were identified through PubMed $(n=376)$, Cochrane Library $(n=102)$, Embase $(n=$ $859)$, and OVID $(n=237)$, and another 10 records were identified through other sources. After the removal of duplicates $(n=854)$, 720 articles were screened for relevance based on the title and abstract. Finally, 191 articles were eligible for inclusion, of which 179 were excluded for reasons of "without fulltext", "not treated with LP and HA" and some other reasons. The remaining 12 studies were included in this meta-analysis (19-30) (details are shown in Figure 1). 


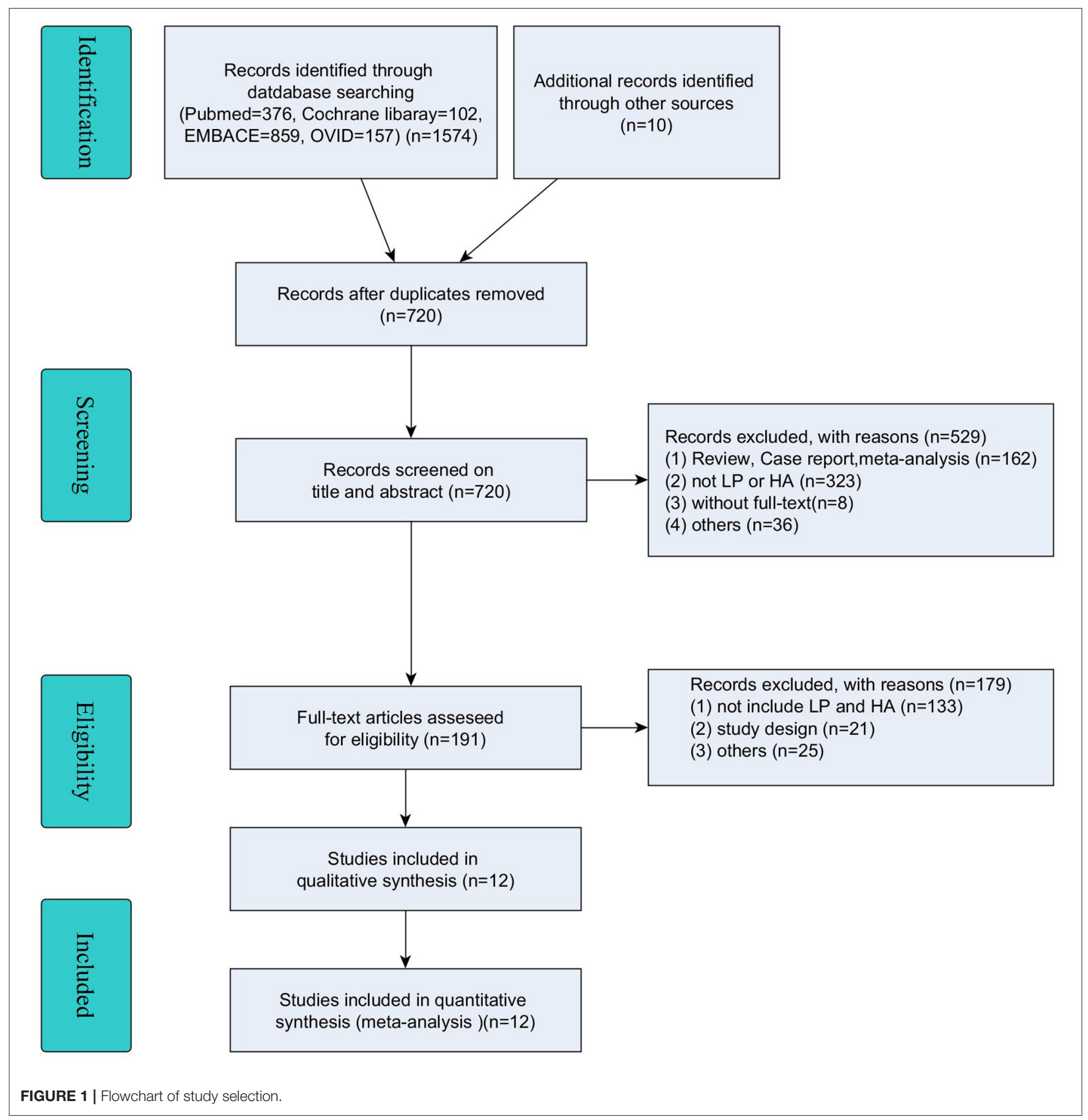

\section{Characteristics and Qualifications of Included Studies}

The characteristics of all the 12 included articles are summarized and shown in Table 1. Of all the included articles, one was a randomized controlled trial (RCT), two were prospective studies (PROs), and nine were retrospective case-control studies (CCSs), which were from four different countries (five from China, four from the United States, two from Switzerland, and one from Italy). A total of 613 patients in the LP group and 345 patients in the HA group were included in this meta-analysis. The article quality assessment and main observation indices are presented in Tables 2, 3, respectively.

\section{Comparison of Complications}

Nine studies reported that the complication rate, with a total of 147 patients (54 in the HA group and 93 in the LP group), was analyzed with a fixed effects model and showed no heterogeneity in each study $\left(P=0.115, I^{2}=38.1 \%\right)$. The results showed that the 
TABLE 1 | Characteristics of the included studies.

\begin{tabular}{|c|c|c|c|c|c|c|c|c|}
\hline References & Country & $\begin{array}{l}\text { Study design/Evidence } \\
\text { level }\end{array}$ & Age & \multicolumn{2}{|c|}{ Gender (M/F) } & $\begin{array}{l}\text { Fracture } \\
\text { type }\end{array}$ & $\begin{array}{l}\text { Follow-up time } \\
\text { (months) }\end{array}$ & Outcome \\
\hline Bastian and Hertel (22) & Switzerland & Pro/ III & 60 & 33 & 44 & Neer II-IV & 56 & $\mathrm{HA}$ \\
\hline Wang et al. (27) & China & $\mathrm{CCS} / \mathrm{III}$ & 49 & 10 & 12 & Neer III-IV & 20 & NR \\
\hline Zhang et al. (28) & China & $\mathrm{CCS} / \mathrm{III}$ & 67.7 & 30 & 28 & Neer III-IV & 28 & NR \\
\hline Cai et al. (23) & China & $\mathrm{RCT} / \mathrm{III}$ & 71.9 & $3 / 16$ & $2 / 11$ & Neer IV & 24 & $\mathrm{HA}$ \\
\hline Lu and TM (29) & China & CCS/ III & 67 & 22 & 26 & Neer IV & $>6$ & NR \\
\hline Chalmers et al. (21) & America & $\mathrm{CCS} / \mathrm{III}$ & $\mathrm{H} 72 / \mathrm{L} 71$ & 9 & 9 & Neer III-IV & 12 & $\mathrm{HA}$ \\
\hline Thorsness et al. (30) & America & $\mathrm{CCS} / \mathrm{III}$ & H69.3/L64 & $17 / 66$ & $105 / 225$ & Neer III-IV & / & NR \\
\hline Chen et al. (25) & China & Pro / III & H64/L68 & 30 & 30 & Neer IV & 24 & LP \\
\hline Repetto et al. (26) & Italy & $\mathrm{CCS} / \mathrm{III}$ & 67.7 & 24 & 19 & Neer III-IV & 39.7 & NR \\
\hline
\end{tabular}

$R C T$, randomized controlled trial; CCS, retrospective case-control study; Pro, prospective study; HA, hemiarthroplasty; LP, locking plate fixation; NR, neutral; M/F, male/female.

TABLE 2 | Methodological quality assessment of included studies.

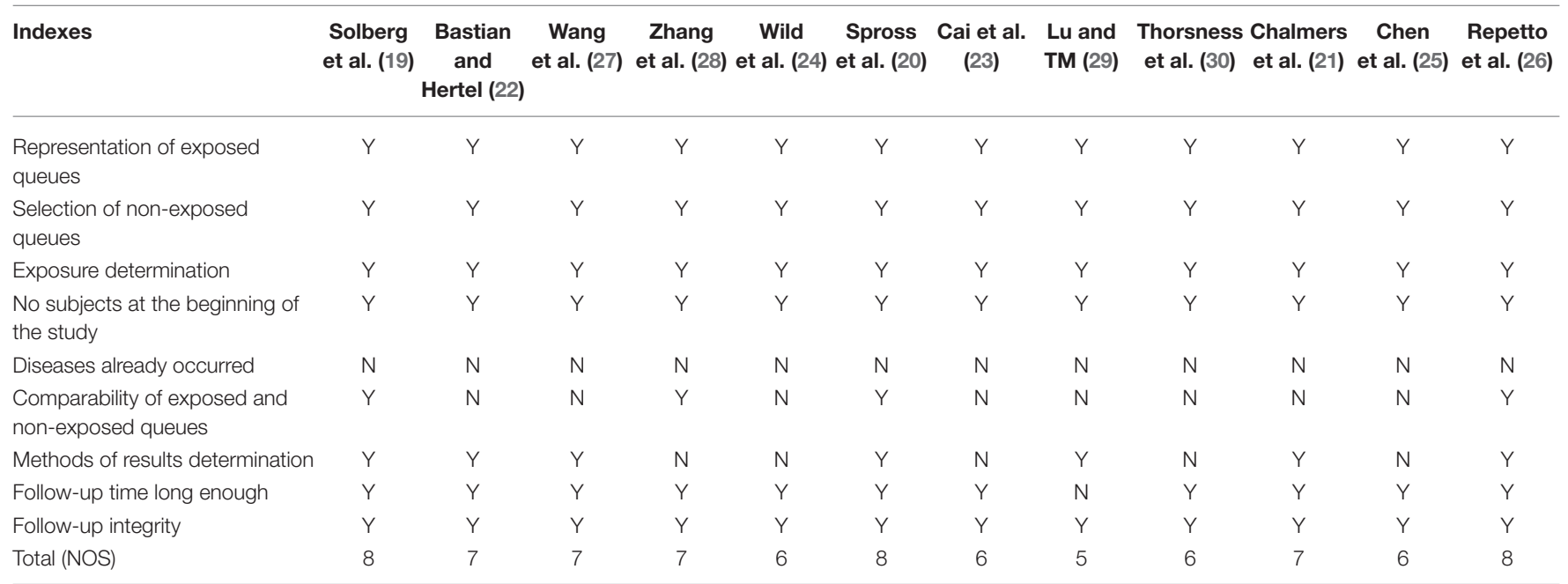

The evaluation criteria for follow-up time was over 12 months, and follow-up integrity was $>80$.

TABLE 3 | Main observation indexes.

\begin{tabular}{|c|c|c|c|c|c|c|c|c|c|c|c|c|}
\hline \multirow[t]{2}{*}{ References } & \multicolumn{2}{|c|}{ Complications } & \multicolumn{2}{|c|}{ Reoperation rate } & \multicolumn{8}{|c|}{ Functional indexes } \\
\hline & HA & LP & HA & LP & HA & LP & HA & LP & HA & LP & HA & LP \\
\hline Solberg et al. (19) & 10 & 19 & 8 & 11 & $60.65 \pm 0.9$ & $68.69 \pm 0.5$ & / & / & / & / & / & / \\
\hline Bastian and Hertel (22) & 10 & 24 & 4 & 7 & $70.01 \pm 1.25$ & $77.01 \pm 5.25$ & / & / & / & / & / & / \\
\hline Wang et al. (27) & 0 & 2 & I & / & $65.15 \pm 0.3$ & $69.66 \pm 0.7$ & I & I & I & / & I & I \\
\hline Spross et al. (20) & 17 & 14 & 1 & 10 & $54.41 \pm 0.0$ & $65.21 \pm 7.0$ & / & / & / & / & / & / \\
\hline Cai et al. (23) & 1 & 1 & 3 & 3 & 72.9 & 60.7 & / & / & / & / & / & / \\
\hline Lu and TM (29) & 3 & 3 & / & / & $70.41 \pm 2.4$ & $73.61 \pm 1.0$ & / & / & / & / & / & / \\
\hline Chalmers et al. (21) & 7 & 23 & / & / & / & / & / & / & / & / & / & / \\
\hline Thorsness et al. (30) & 1 & 1 & / & / & I & / & $66 \pm 31$ & $75 \pm 15$ & $7 \pm 4$ & $8 \pm 4$ & $34 \pm 7$ & $34 \pm 6$ \\
\hline
\end{tabular}




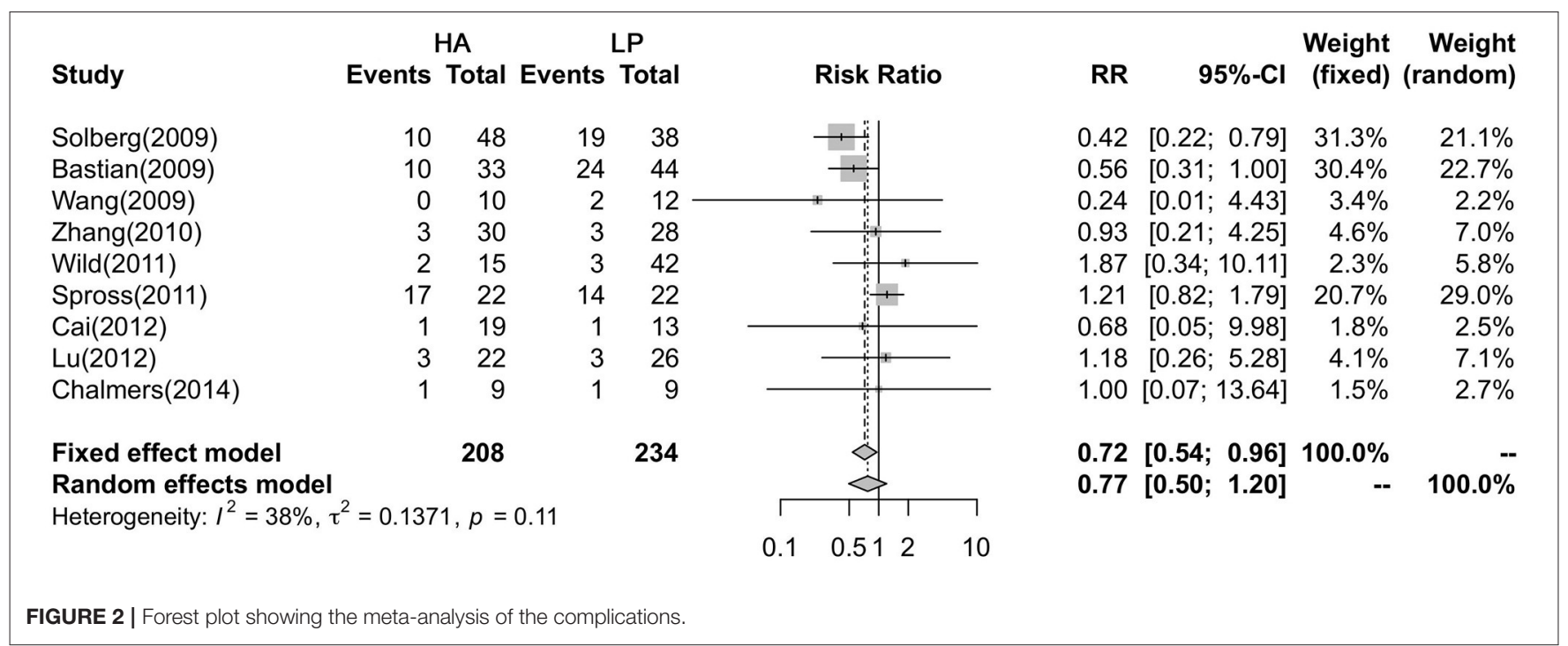

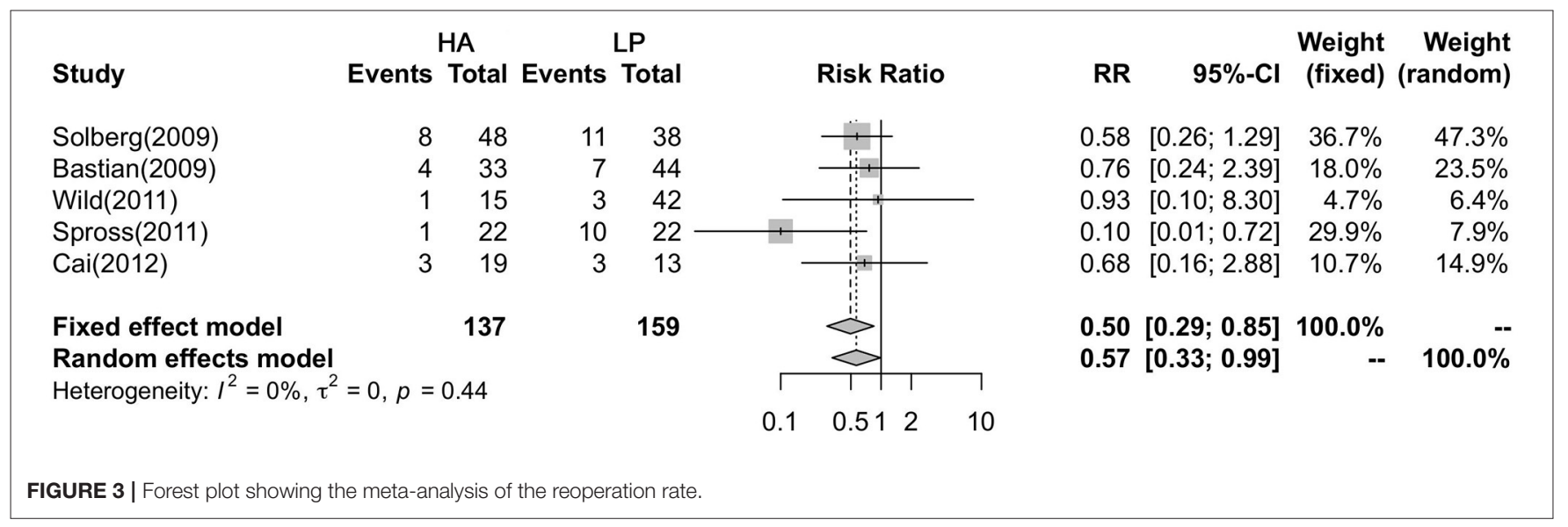

LP group had a higher postoperative complication rate than the HA group (29.91 vs. $22.6 \%, P=0.024$ ) (Figure 2).

\section{Comparison of Reoperation Rate}

A fixed effects model was utilized to analyze the differences in reoperation rates in five studies. The results showed that there was no heterogeneity among the five studies $\left(P=0.443, I^{2}=0 \%\right)$. In addition, the results showed a higher reoperation rate in the HA group than in the LP group $(R R=0.495,95 \%$ CI:0.289-0.848; $P=0.01)$ (Figure 3).

\section{Comparison of Functional Outcomes}

The CMS, ASES, SF-12V2, and SST were used to estimate the functional outcome of the two groups. The meta-analysis showed no heterogeneity among the nine studies $\left(P=0.015, I^{2}=57.7 \%\right)$, and the CMS in the LP group was better than that in the HA group (SMD $=-0.585,95 \% \mathrm{CI}:-0.874$ to $-0.296 ; P<0.001$ ) (Figure 4A). In addition, the meta-analysis showed that there were significant differences between ASES (95\% CI: -1.114 to $-0.099 ; P=0.019)$ and SST (95\% CI: -1.135 to $-0.118 ; P=$ $0.016)$, without heterogeneity $\left(P=0.553, I^{2}=0 \% ; P=0.342\right.$,
$I^{2}=0 \%$; respectively), and that there were no differences in SF-12V2 (95\% CI: -0.844 to $-0.159 ; P=0.18$ ) (Figures 4B-D).

\section{Publication Bias Recognition}

Publication bias analysis showed that the complications, reoperation rate, and CMS of Begg's test funnel plot statistics were $0.466,1.000$, and 0.602, respectively (Figures 5A-C). Almost all the scattered studies were located in a funnel map, suggesting that the publication bias of the included studies was small (Figure 5).

\section{DISCUSSION}

As an important functional unit of the body, shoulder joint function will be seriously affected after trauma, and reasonable treatment seems important. To date, the treatment of PHFs is still a controversial topic and a major challenge for surgeons. In particular, complex fracture patterns usually lead to pain and functional patterns, which lead many clinicians to regard threeor four-part fractures as indications for surgical treatment (10). However, whether the surgical method can achieve a satisfactory 


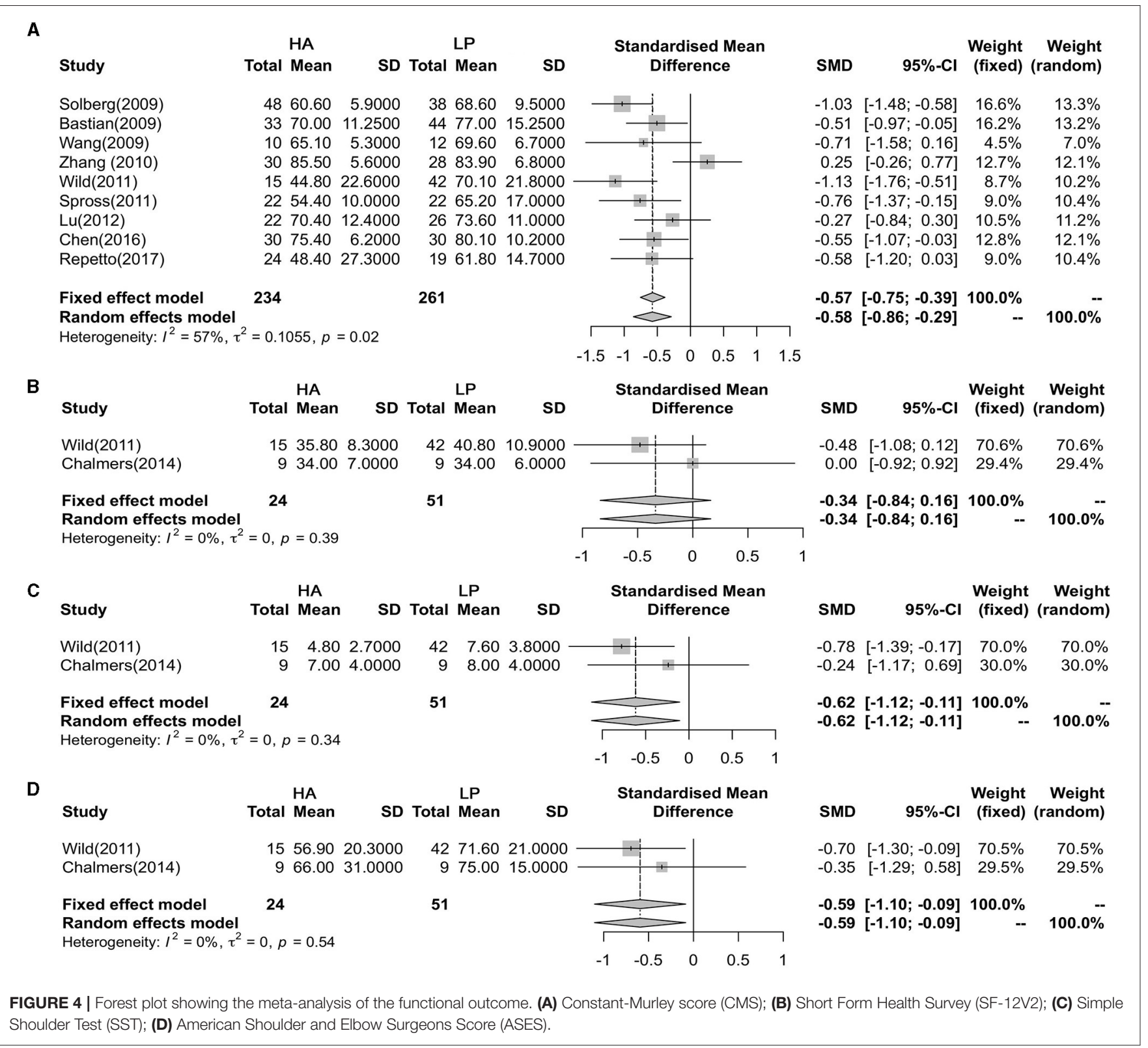

shoulder joint function is still controversial (31-33). The metaanalysis from the selected literature showed that LP has more advantages in the evaluation of postoperative function, and that the literature was heterogeneous.

The CMS, ASES, SST and SF-12v2 were used extensively for clinical evaluation standards for shoulder joints (34); the higher the score, the better the shoulder function. The use of CMS helps to perceive the diversity of consequences, especially the power of evaluation and scope of activity, which aroused the concern of examiners on the lack of evaluation standards and potential nonobserver bias. Previous reports have shown that the CMS among female patients over 60 years old was 69-70, and that it was 7583 in male patients (35). In this study, we found a significant difference in the total CMS, and ASES and SST scores between the
LP and HA groups. After operation, all patients in both groups obtained satisfactory shoulder function.

The incidence and types of complications vary from one document to another, such as fracture nonunion, dislocation, infection, avascular necrosis (AVN), internal fixation, or prosthesis loosening or rupture $(36,37)$. In this study, the total postoperative complication rate of the included cases was analyzed, and the results showed a higher complication rate in the LP group $(29.91 \%$ vs. $22.6 \%)$. In line with previous findings (38), this study showed an incidence of complications of $26.47 \%$. AVN is an important complication of LP and occurs in 4 to $55 \%$ of humeral heads $(19,20)$. Due to the removal of humeral head in patients treated with HA, AVN may not occur after surgery. From a clinical perspective, the relative risk 

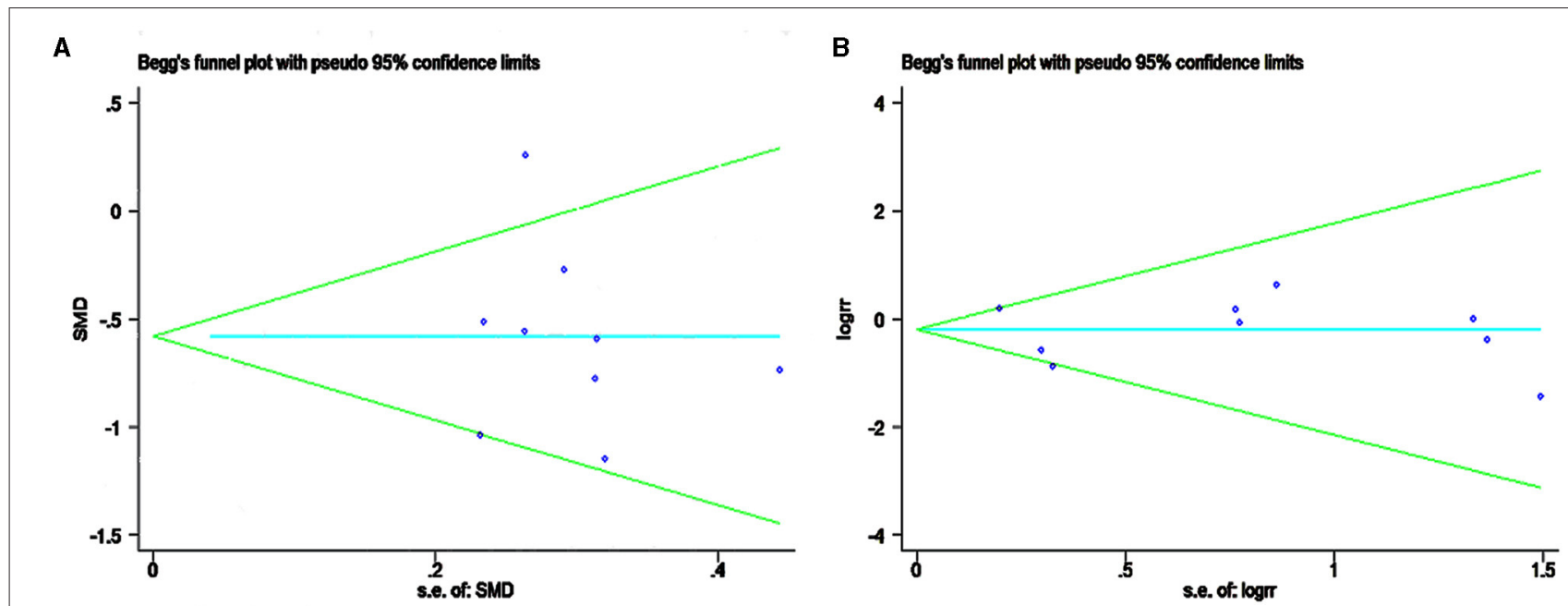

C Begg's funnel plot with pseudo $95 \%$ confidence limits


E Begets furnel plat with peeudo $95 \%$ confidence lints

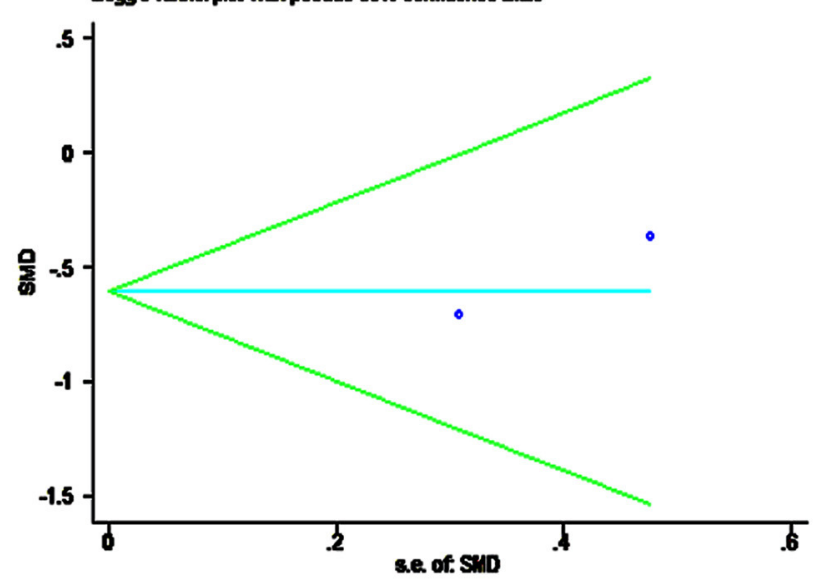

$\mathbf{F}$

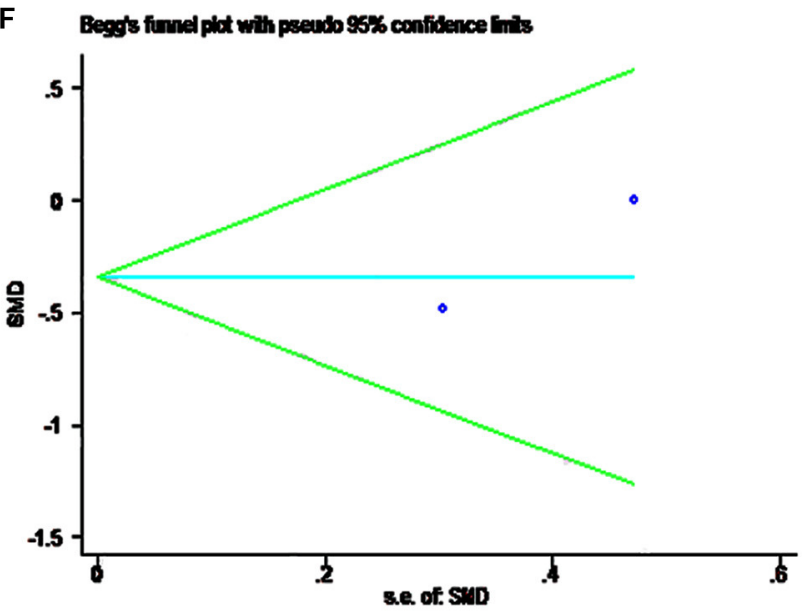

FIGURE 5 | Funnel plot showing the meta-analysis of publication bias recognition

(A) CMS; (B) complications; (C) reoperation rate; (D) SST; (E) ASES; (F) SF-12V2.

(RR) of AVN in the LP group was higher than that in the HA group. Additionally, the meta-analysis results also support this conclusion regarding the complications of loosening and displacement (data not shown).
Although complications were the cause of reoperation, not all of them were reoperated on. In the involved literature, Spross (20) considered the height of the prosthesis as a complication, but it did not undergo reoperation. This may explain why 
there was no difference in complications between the LP and HA groups, but a difference in the reoperation rate. However, because of different expectations of patients and/or physicians and possibly the exit of observation bias, reoperation rate has not been mentioned in some literature $(21,30)$. Inconsistent with some studies, the meta-analysis showed a higher reoperation rate in the HA group than in the LP group (39.71\% vs. $25.94 \%$ ), which suggested an advantage for the LP group.

There are several weaknesses in this study, which may affect the applicability of the conclusions. First, the methodological quality of published literature was insufficient, and the sample size of some literature was small, indicating inadequate statistical power. In addition, the simple method described by Hozo (18) was conducted to calculate the SD, which might cause a deviation in the results, but this deviation may decrease with increasing the sample size. In addition, the literature included in this article lacks long-term prospective randomized controlled trials. This is mainly due to the characteristics of clinical work, and it seems difficult to achieve a genuine randomized controlled trial. Multicenter, large-sample RCTs should be included to ensure that the results are more convincing. Additionally, a stratified analysis based on age, sex, level of motion, degree of fracture displacement, and degree of articular surface accumulation may compensate for the deficiency of this article. Moreover, the studies included in the meta-analysis were

\section{REFERENCES}

1. Viprey M, Caillet P, Canat G, Jaglal S, Haesebaert J, Chapurlat R, et al. Low osteoporosis treatment initiation rate in women after distal forearm or proximal humerus fracture: a healthcare database nested cohort study. PLoS ONE. (2015) 10:e0143842. doi: 10.1371/journal.pone.0143842

2. Dimai HP, Svedbom A, Fahrleitner-Pammer A, Pieber T, Resch H, Zwettler E, et al. Epidemiology of proximal humeral fractures in Austria between 1989 and 2008. Osteoporos Int. (2013) 24:2413-21. doi: 10.1007/s00198-013-2339-0

3. Court-Brown CM, Garg A, McQueen MM. The epidemiology of proximal humeral fractures. Acta Orthop Scand. (2001) 72:365-71. doi: 10.1080/000164701753542023

4. Court-Brown CM, Caesar B. Epidemiology of adult fractures: A review. Injury. (2006) 37:691-7. doi: 10.1016/j.injury.2006.04.130

5. Passaretti D, Candela V, Sessa P, Gumina S. Epidemiology of proximal humeral fractures: a detailed survey of 711 patients in a metropolitan area. J Shoulder Elbow Surg. (2017) 26:2117-24. doi: 10.1016/j.jse.2017.05.029

6. Roux A, Decroocq L, El Batti S, Bonnevialle N, Moineau G, Trojani C, et al. Epidemiology of proximal humerus fractures managed in a trauma center. Orthop Traumatol Surg Res. (2012) 98:715-9. doi: 10.1016/j.otsr.2012.05.013

7. Robinson CM, Stirling PHC, Goudie EB, MacDonald DJ, Strelzow JA. Complications and long-term outcomes of open reduction and plate fixation of proximal humeral fractures. J Bone Joint Surg Am. (2019) 101:2129-39. doi: $10.2106 /$ JBJS.19.00595

8. Maier D, Jaeger M, Izadpanah K, Strohm PC, Suedkamp NP. Proximal humeral fracture treatment in adults. J Bone Joint Surg Am. (2014) 96:251-61. doi: 10.2106/JBJS.L.01293

9. Verbeek PA. Akker- Scheek VDI, Went KW, Diercks RL. Hemiarthroplasty versus angle-stable locking compression plate osteosynthesis in the treatment of three-and four- part fractures of the proximal humerus in the elderly: design of a randomized controlled trial. BMC Musculoskelet Disord. (2012) 13:16. doi: 10.1186/1471-2474-13-16

10. Vrotsou K, Avila M, Machon M, Mateo-Abad M, Pardo Y, Garin O, et al. Constant-Murley Score: systematic review and standardized evaluation of a relatively poor level of evidence (level III), and more studies are needed.

\section{CONCLUSIONS}

Through meta-analysis, this study determined the clinical effects of LP vs. HA on PHFs. The results showed that patients treated with LP exhibited better clinical efficacy in some aspects when compared with HA, which has the potential to help guide decision-making and weigh risks and benefits. However, limited by small sample size and RCT study, there is no consensus on which treatment is more suitable and advantageous.

\section{DATA AVAILABILITY STATEMENT}

The raw data supporting the conclusions of this article will be made available by the authors, without undue reservation.

\section{AUTHOR CONTRIBUTIONS}

JD and SZ conceived of the design of the study. YY, LZ (4th Author), and LZ (5th Author) performed the study, collected the data, and contributed to the design of the study. KY prepared the manuscript. XX edited the manuscript. All authors have read and approved the final manuscript.

in different shoulder pathologies. Qual Life Res. (2018) 27:2217-26. doi: 10.1007/s11136-018-1875-7

11. Noyes MP, Kleinhenz B, Markert RJ, Crosby LA. Functional and radiographic long-term outcomes of hemiarthroplastynfor proximal humeral fractures. $J$ Shoulder Elbow Surg. (2011) 20:372-7. doi: 10.1016/j.jse.2010.06.009

12. Boileau P, Krishan SG, Tinsi L, Walch G, Coste JS, Molé D. Tuberosity malposition and migration: reasons for poor outcomes after hemiarthroplasty for displaced fractures of the proximal humerus. J Shoulder Elbow Surg. (2002) 11:401-12. doi: $10.1067 / \mathrm{mse} .2002 .124527$

13. Cvetanovich GL, Chalmers PN, Verma NN, Nicholson GP, Romeo AA. Open reduction internal fixation has fewer short-term complications than shoulder arthroplasty for proximal humeral fractures. J Shoulder Elbow Surg. (2016) 25:624-31 e3. doi: 10.1016/j.jse.2015.09.011

14. Miranda MA. Locking plate technology and its role in osteoporotic fractures. Injury. (2007) 38:S35-9. doi: 10.1016/j.injury.2007.08.009

15. Robinson CM, Page RS, Hill RM, Sanders DL, Court-Brown CM, Wakefield AE. Primary hemiarthroplasty for treatment of proximal humeral fractures. J Bone Joint Surg Am. (2003) 85:1215-23. doi: 10.2106/00004623-200307000-00006

16. Young SW, Segal BS, Turner PC, Poon PC. Comparison of functional outcomes of reverse shoulder arthroplasty versus hemiarthroplasty in the primary treatment of acute proximal humerus fracture. ANZ J Surg. (2010) 80:789-93. doi: 10.1111/j.1445-2197.2010.05342.x

17. Handoll $\mathrm{HH}$, Brorson S. Interventions for treating proximal humeral fractures in adults. Cochrane Database Syst Rev. (2015) 11:CD000434. doi: 10.1002/14651858.CD000434.pub4

18. Hozo SP, Djulbegovic B, Hozo I. Estimating the mean and variance from the median, range, and the size of a sample. BMC Med Res Methodol. (2005) 5:13. doi: 10.1186/1471-2288-5-13

19. Solberg BD, Moon CN, Franco DP, Paiement GD. Surgical treatment of three and four-part proximal humeral fractures. J Bone Joint Surgery-Series A. (2009) 91:1689-97. doi: 10.2106/JBJS.H.00133

20. Spross C, Platz A, Erschbamer M, Lattmann T, Dietrich M. Surgical treatment of neer group vi proximal humeral fractures: Retrospective comparison of 
PHILOS $®$ and hemiarthroplasty. Clin Orthop Relat Res. (2012) 470:2035-42. doi: 10.1007/s11999-011-2207-1

21. Chalmers PN, Slikker W. 3rd, Mall NA, Gupta AK, Rahman Z, Enriquez D, et al. Reverse total shoulder arthroplasty for acute proximal humeral fracture: comparison to open reduction-internal fixation and hemiarthroplasty. $J$ Shoulder Elbow Surg. (2014) 23:197-204. doi: 10.1016/j.jse.2013.07.044

22. Bastian JD, Hertel R. Osteosynthesis and hemiarthroplasty of fractures of the proximal humerus: outcomes in a consecutive case series. J Shoulder Elbow Surg. (2009) 18:216-9. doi: 10.1016/j.jse.2008.09.015

23. Cai M, Tao K, Yang C, Li S. Internal fixation versus shoulder hemiarthroplasty for displaced 4-part proximal humeral fractures in elderly patients. Orthopedics. (2012) 35:e1340-6. doi: 10.3928/01477447-20120822-19

24. Wild JR, DeMers A, French R, Shipps MR, Bergin PF, Musapatika D, et al. Functional outcomes for surgically treated 3- and 4part proximal humerus fractures. Orthopedics. (2011) 34:e629-33. doi: 10.3928/01477447-20110826-14

25. Chen H, Ji X, Gao Y, Zhnag L, Zhang Q, Liang X, et al. Comparison of intramedullary fibular allograft with locking compression plate versus shoulder hemi-arthroplasty for repair of osteoporotic four-part proximal humerus fracture: Consecutive, prospective, controlled, and comparative study. Orthop Traumatol Surg Res. (2016) 102:287-92. doi: 10.1016/j.otsr.2015.12.021

26. Repetto I, Alessio-Mazzola M, Cerruti P, Sanguineti F, Formica M, Felli L. Surgical management of complex proximal humeral fractures: pinning, locked plate and arthroplasty: Clinical results and functional outcome on retrospective series of patients. Musculoskeletal Surgery. (2017) 101:153-8. doi: 10.1007/s12306-017-0451-6

27. Wang DL, Ruan DK, Yin Q, Li HF, Wang PJ, QH. Surgical treatment for complicated proximal humeral fractures and analysis of efficacy. Chin J Bone Joint Injury. (2009) 24:985-7. doi: 10.1111/os.12486

28. Zhang J, Di Z, He Z, Feng JRX. Comparison of humeral head replacement and internal fixation for the treatment of 3 parts and 4 parts fractures of proximal humerus in the elderly. China J Orthop Traumatol. (2010) 23:435. doi: 10.3969/j.issn.1003-0034.2010.06.0013

29. Lu J, TM Z. Comparative research of the outcomes after two different methods for treatment of four-part proximal humerus fractures. J Pract Orthop. (2012) 18:115-7. doi: 10.1016/j.jse.2018.07.019

30. Thorsness R, Iannuzzi J, Noyes K, Kates S, Voloshin I. Open reduction and internal fixation versus hemiarthroplasty in the management of proximal humerus fractures. Geriatr Orthop Surg Rehabil. (2014) 5:56-62. doi: $10.1177 / 2151458514527292$

31. Helmy N, Hintermann B. New trends in the treatment of proximal humerus fractures. Clin Orthop Relat Res. (2006) 442:100-8. doi: 10.1097/01.blo.0000194674.56764.c0
32. Lanting B, MacDermid J, Drosdowech D, Faber KJ. Proximal humeral fractures: a systematic review of treatment modalities. J Shoulder Elbow Surg. (2008) 17:42-54. doi: 10.1016/j.jse.2007. 03.016

33. Mao F, Zhang DH, Peng XC, Liao Y. Comparison of surgical versus non-surgical treatment of displaced 3- and 4-part fractures of the proximal humerus: a meta-analysis. J Invest Surg. (2015) 28:215-24. doi: $10.3109 / 08941939.2015 .1005781$

34. Constant CR, Gerber C, Emery RJH, Søjbjerg JO, Gohlke F, Boileau P. A review of the Constant score: Modifications and guidelines for its use. $J$ Shoulder Elbow Surg. (2008) 17:355-61. doi: 10.1016/j.jse.2007.06.022

35. Constant CR, Murley AH. A clinical method of functional assessment of the shoulder. Clin Orthop Relat Res. (1987) 160-4. doi: 10.1097/00003086-198701000-00023

36. Cuff DJ, Pupello DR. Comparison of hemiarthroplasty and reverse shoulder arthroplasty for the treatment of proximal humeral fractures in elderly patients. J Bone Joint Surg Am. (2013) 95:2050-5. doi: 10.2106/JBJS.L. 01637

37. Gupta AK, Harris JD, Erickson BJ, Abrams GD, Bruce B, McCormick F, et al. Surgical management of complex proximal humerus fractures-a systematic review of 92 studies including 4500 patients. JOrthop Trauma. (2015) 29:54-9. doi: 10.1097/BOT.0000000000000229

38. Sproul RC, Iyengar JJ, Devcic Z, Feeley BT. A systematic review of locking plate fixation of proximal humerus fractures. Injury. (2011) 42:408-13. doi: 10.1016/j.injury.2010.11.058

Conflict of Interest: The authors declare that the research was conducted in the absence of any commercial or financial relationships that could be construed as a potential conflict of interest.

Publisher's Note: All claims expressed in this article are solely those of the authors and do not necessarily represent those of their affiliated organizations, or those of the publisher, the editors and the reviewers. Any product that may be evaluated in this article, or claim that may be made by its manufacturer, is not guaranteed or endorsed by the publisher.

Copyright $\odot 2021$ Deng, Zhang, Yu, Zhang, Zhang, Jiang, Yang and Xi. This is an open-access article distributed under the terms of the Creative Commons Attribution License (CC BY). The use, distribution or reproduction in other forums is permitted, provided the original author $(s)$ and the copyright owner(s) are credited and that the original publication in this journal is cited, in accordance with accepted academic practice. No use, distribution or reproduction is permitted which does not comply with these terms. 